\title{
A Study on the Development Strategy of Linyi's Air Logistics
}

\author{
Ming $\mathrm{Lu}^{1, \mathrm{a}}$ \\ ${ }^{1}$ College of Aeronautics, Florida Institute of Technology, Melbourne 32901, United States of America \\ ${ }^{a}$ Corresponding author: mlu2019@my.fit.edu
}

\begin{abstract}
In the 21 st century, with the integration of the global economy and the increasingly frequent trade between countries and regions globally, the logistics industry is playing an increasingly important role in economic development. Air goods are an essential part of the logistics industry. Its flow speed, significant span characteristics, in fresh, valuable goods and other aspects of the logistics play a great advantage, and become the current world countries compete for the development of important logistics field. Linyi is the largest logistics base in northern China, known as "Jiangbei Logistics Capital," in its many years of development, land logistics is the main field, the development of aviation logistics in Linyi area is relatively slow. With the development of the current economy and society, the lack of development of aviation logistics has become the shortboard and bottleneck of Linyi's development of logistics, so that there is a certain gap between Linyi and the title of "logistics capital."

In view of this, Shandong Province and Linyi, in the 14th Five-Year Plan for the development of Linyi aviation logistics, put forward a specific development plan to maximize the lack of Linyi aviation logistics development. In this situation, this article selects the Linyi aviation logistics development strategy as the research object, through the analysis of the current related basic theory, and with the help of the related IFE matrix, SWOT, VTIO model research methods, such as aviation logistics development of Linyi's external environment, internal resources, and ability, has the strengths, weaknesses, opportunities, and challenges facing are fully analyzed. On this basis, the strategic objectives and core competitiveness of Linyi aviation logistics are positioned, the development strategy of Linyi aviation logistics is put forward, the development steps of Linyi aviation logistics are designed, and the measures and suggestions for the implementation of the strategy are proposed.

Through the study of this article, on the competitiveness of the aviation logistics development of Linyi positioning, for the later development strategies and safeguard measures, can help the Linyi perfect itself in the development of aviation logistics development strategy, promote better and faster development of Linyi aviation logistics industry, at the same time can also provide a reference for other similar aviation logistics development in the region and using for reference.
\end{abstract}

Keywords: Linyi; Aviation logistics, Development strategy, Measures suggested.

\section{INTRODUCTION}

Linyi, which is located in the southern part of Shandong Province, is an important logistics base in China and has become the largest distribution center for small commodities in northern China after years of development. Recently, in the 14th Five-Year Plan, the Government in Linyi has put forward to improve the modern logistics infrastructure and develop the modern logistics industry with a high threshold and comprehensive planning. After nearly two decades of development, Linyi has achieved the goal of having a complete modern logistics infrastructure, diversified logistics methods, and an information-based logistics platform, but it is still a long way from being a modern logistics base. At present, logistics transportation in Linyi is still mainly road transportation, and there is no access to the sea, so it is not compatible with sea transportation. Although the airport has been established and has some freight capacity, the air freight volume is very limited, the air freight efficiency is low, and there is no international route. If companies in Linyi want to export, they have to transfer to Beijing or Shanghai. Therefore, although Linyi has made certain achievements in logistics development, it still cannot match the goal of a modern logistics base. To achieve the goal of a modern logistics base, Linyi must 
vigorously improve its logistics elements, optimize its structure and enhance its competitiveness.

Linyi currently has an extremely strong infrastructure inland transportation, and there is no possibility of developing sea transportation due to the lack of sea access. Therefore, in developing the modern logistics industry, it must pay attention to air logistics and vigorously develop air logistics to make up for the gap in the current industry development. In view of this, this paper selects Linyi's air logistics development strategy as the research object and uses the strategic development research method based on relevant theories to analyze Linyi's development of air logistics and propose relevant implementation strategies.

Based on the current logistics development situation in Linyi, this study analyzes the internal resources and advantages of Linyi's air logistics industry and external environment and provides strategic help for the development of air logistics in Linyi. The study will, on the one hand, improve the research gaps in the development of air logistics in prefecture-level cities in China and improve the research theory of the modern logistics industry; on the other hand, it will provide actionable strategic suggestions for the development of air logistics in Linyi and promote the better and faster development of the logistics industry in Linyi.

\section{CURRENT STATUS OF AVIATION LOGISTICS DEVELOPMENT IN LINYI}

Linyi is an important trade and logistics base in the north of China, and its logistics transportation mode is mainly by land transport. At present, Linyi Airport has developed into a medium-sized airport for domestic civil transportation. The airport now covers an area of 263 hectares, with a runway of 3200 meters long and 60 meters wide, two vertical liaison lanes, two end liaison lanes, two by-pass liaison lanes, two fast exit taxiways, and one parallel taxiway of 3200 meters, flight area technical level 4D, fire rescue level 7; the apron area is 160,000 square meters, which can The apron area is 160,000 square meters, which can meet the needs of 1 Class D, 20 Class C and 14 Class B aircraft parking at the same time; the existing terminal building is 17,000 square meters, designed according to the aviation business volume of 2.5 million passengers and peak hour passenger throughput of 1,250 passengers; the ATC building is 1,800 square meters, equipped with international advanced all-weather ATC, navigation, meteorological, communication and lighting facilities; the general aviation complex is 4,790 square meters. The air cargo terminal and pick-up center covers an area of 29,000 square meters, with two depots for domestic and international departures and arrivals, and the functional settings basically meet the standards of modern logistics requirements. At present, Linyi International Airport has operated 38 routes with 21 airlines, including nine international routes; 37 navigable cities, including seven international members; 39 navigable airports, including seven international members. In 2018, Linyi International Airport achieved 2,006,200 inbound and outbound passenger trips, an increase of $51.06 \%$ year-onyear, ranking 66th in the national transport airports and the fourth in the national transport airports and the first airport in East China. Among them, 56,000 international arrivals and departures were recorded, representing yearon-year growth of $235 \%$. The cargo and mail throughput is $8,036.64$ tons, an increase of $31.13 \%$ year-on-year. The flight routes and passenger throughput grew by leaps and bounds.

In 2019, Linyi was approved by the State Council to approve the official opening of the aviation port at Linyi Qiyang International Airport, and the internationalization of aviation logistics is also being promoted in earnest. An international air cargo terminal meeting the requirements of customs supervision has now been basically built, and the construction of Linyi Airport International Express Supervision Center has started and is scheduled to be put into use within the year, which will gradually open international express and cross-border e-commerce business in the future.

\section{ANALYSIS OF DEVELOPMENT ENVIRONMENT OF AVIATION LOGISTICS IN LINYI}

\subsection{Analysis of the external environment for the development of aviation logistics in Linyi}

With the rapid development of our country and the global economy and society, the demand for air transportation is bound to increase. According to the forecast of relevant professional bodies, the global economic conference will grow by $4 \%$ until 2040 , and the demand for fresh goods and goods that are extremely difficult to store is bound to grow significantly, which provides market space for the development of air transportation. However, the overall air logistics market is becoming increasingly competitive. Within the industry, Linyi is facing competition from many regions inside and outside the province to develop air logistics. Yantai, Qingdao, and Rizhao are developing air transportation on a large scale; outside the province, it is also facing competition from Jiangsu, Henan, Hebei, and Tianjin, etc. According to the data from the National Civil Aviation Administration, the total number of existing general aviation airports in the country has reached 482 . In terms of suppliers, China's current suppliers of aviation fuel and aircraft are monopolistic industries, especially fuel follows the market, resulting in frequent cost fluctuations and high costs. In terms of consumer bargaining, due to a large number of airports, consumers have a wide choice, high service requirements, and strong bargaining power, and many consumers also operate both 
land and sea transportation. In terms of substitutes, with the increasing scale of high-speed rail construction and a considerable number of foreign countries starting to build high-speed rail, the advantages of high-speed rail's rapidity are reducing the advantages of air transportation. In terms of potential competitors, due to the huge current market demand, the gradual relaxation of civil aviation regulatory policies, and the lowering of the market entry threshold, especially Linyi's great demand for air transportation and its own weak capacity, lead to the fact that airlines from Shanghai, Tianjin, Beijing and Jiangsu regions will gradually move to Linyi's material trade area and seize Linyi Airport's market share.

\subsection{Analysis of internal capacity of Linyi Air Logistics Development}

Internal capabilities are the driving force for business development, and Linyi needs to have extremely strong internal capabilities to support the development of its air logistics industry. From the perspective of air logistics, there must be sufficient cargo and mail collection and distribution capacity, cargo service assurance capacity, extension capacity, and international aviation customs clearance capacity. [1]

In terms of cargo and mail collection and distribution capacity, Linyi Airport has built a 29,000 square meter air cargo terminal and sorting center with a design cargo and mail throughput of 20,000 tons per year, which meets the standard of medium-sized civil transport airports. In addition, 11 general aviation airports will be built within Linyi, and the future cargo and mail throughput capacity can reach more than 100 million tons.

In terms of cargo service capacity, Linyi Airport can currently park Class D, Class C, and Class B aircraft and can park up to 35 aircraft at the same time. Linyi Airport's air cargo terminal can provide loading and unloading guarantees for all types of aircraft and currently has 20 general shuttle buses, six tractor trucks, six roller board trucks, seven forklifts, 2; transfer trucks, and two multifunctional platform trucks to meet the loading and unloading needs. However, there is a lack of a perfect information management platform, and there is the phenomenon of unreasonable loading and unloading arrangement.
In terms of extended service capacity, Linyi Airport also has various warehouses to meet the needs of the cold chain, distribution, and small living facilities, in addition to perfect facilities for monitoring, storage, and transportation of dangerous chemicals, and storage of valuables to protect the extended service needs of consumers. However, the overall scale of these facilities is small and requires significant investment for subsequent expansion.

In terms of customs clearance capacity, Linyi Airport International Express Supervision Center has been built and put into operation, the international air cargo terminal has been built and accepted by Qingdao Customs and put into operation, Linyi Airport also has a comprehensive bonded area, Qingdao Customs has a special customs clearance declaration hall at Linyi Airport, and all kinds of customs clearance equipment are available, in order to speed up the development of international aviation business, Linyi Airport also provides customers with 24hour appointment In order to speed up the development of international aviation business, Linyi Airport also provides 24-hour reservation service for customers.

\subsection{IFE Matrix Analysis of the Development of Linyi Air Logistics Development}

The internal resources and capabilities of Linyi's air logistics were analyzed in the previous paper, and here the internal factors of Linyi's air logistics development were scored using the Delphic illegal scoring system, and the final value of each score was the average score scored by the expert group. The IFE matrix for the development of air logistics in Linyi was constructed, as shown in Table 1.

Through the IFE matrix analysis of Linyi's internal resources and capabilities, the strength score is 1.76 , greater than the weakness score of 1.45 , and the total score of internal resources and capabilities is 3.21 , which is more than 2.5. This shows that Linyi's internal resources and capabilities are also in the upper level within the whole industry, and its internal strength is higher than the industry average. [2]

Table 1 Internal resource capacity IFE matrix for the development of air logistics in Linyi

\begin{tabular}{|c|c|c|c|c|c|}
\hline \multicolumn{2}{|c|}{ Factor Indicators } & Factor Description & Weights & Rating & Weighted \\
\hline \multirow{4}{*}{$\begin{array}{l}\text { Advan } \\
\text { tages }\end{array}$} & \multicolumn{2}{|c|}{ Nearly three decades of experience in the industry } & 0.08 & 4 & 0.32 \\
\hline & \multicolumn{2}{|c|}{ Financial resources to meet current operational needs } & 0.08 & 4 & 0.32 \\
\hline & \multicolumn{2}{|c|}{$\begin{array}{c}\text { Abundant human resources to meet the business } \\
\text { development of enterprises }\end{array}$} & 0.05 & 3 & 0.15 \\
\hline & \multicolumn{2}{|c|}{$\begin{array}{c}\text { The logistics industry is large in scale, and the market } \\
\text { base is abundant in space }\end{array}$} & 0.05 & 3 & 0.15 \\
\hline
\end{tabular}




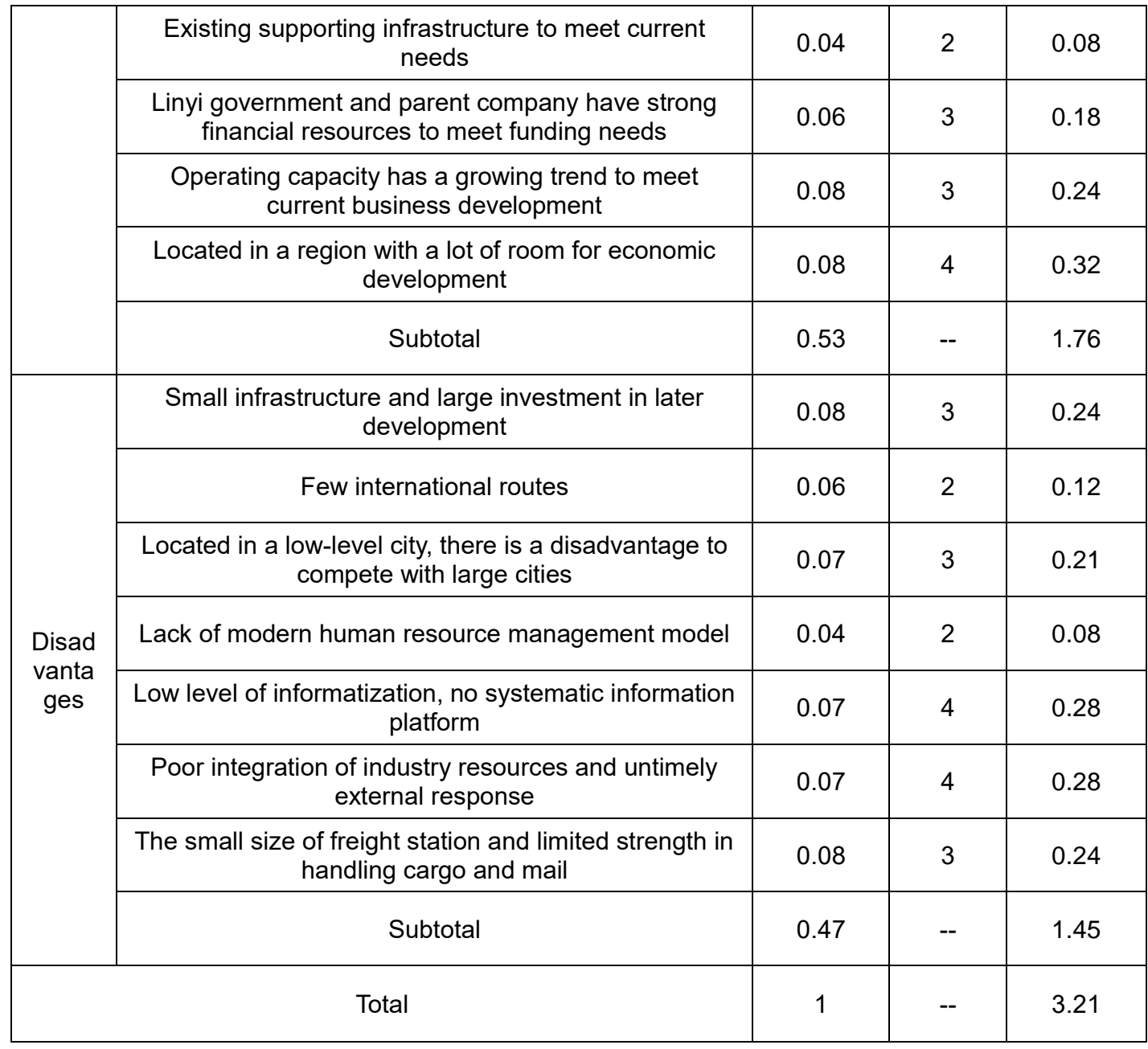

\section{COMPETITIVE ANALYSIS AND STRATEGIC CHOICE OF LINYI AIR LOGISTICS DEVELOPMENT}

\subsection{SWOT Analysis of Linyi Air Logistics Development Strategy}

\subsubsection{Internal advantages}

Linyi, located in the southern part of Shandong Province, has certain internal advantages in developing air logistics. Firstly, it has location advantages, being located at the junction of two developed provinces, Shandong and Jiangsu, with convenient transportation. Secondly, there are industrial advantages, as Linyi has developed into the largest logistics base in the north of China, with abundant cargo sources and a certain branding effect; again, there are policy advantages, as Linyi will build 11 general aviation airports in the future according to the civil aviation development plan of Shandong Province, and will be positioned as an aviation hub in southern Shandong and northern Jiangsu; finally, there is the drive of local economic development, as
Linyi's economy is developing rapidly this year and has leaped to the fourth-largest economy in Shandong Province. Linyi is the fourth largest economical city in Shandong Province, and it will build a national logistics hub for trade services during the period of the 14th FiveYear Plan.

\subsubsection{Internal Disadvantages}

As an ordinary prefecture-level city, there are certain disadvantages in developing aviation logistics, especially in the situation of lots of strong economic cities existed in Shandong Province. First of all, limited financial support, the development of aviation logistics requires a large investment to improve the infrastructure, relying solely on the local Linyi, the financial capacity is limited; secondly, the lack of human resources, due to the region of southern $\mathrm{Lu}$, to attract talent location advantage is not strong, it is difficult to introduce high-tech talent as the support of aviation logistics development. Once again, the management mode is backward. Linyi Airport is a product of separation of affairs and enterprises, with strong color of business management, lack of modern enterprise management system, and perfect information 
system platform, which is not conducive to enterprise development. Finally, the existing infrastructure is weak, with few international routes and the lack of long-term consideration for infrastructure support and airport peripheral planning, resulting in huge investment later.

\subsubsection{External Opportunities}

The current global integration process continues, and international trade and commerce are becoming more frequent. The advantages of air logistics are obvious in the global economic integration, especially the demand for air transportation in industries such as the fresh food industry, high-end manufacturing, and medical and health care is huge. In addition, China has been vigorously implementing supply-side reforms, industrial transfers, and increased policy support for the development of small and medium-sized cities in recent years, and Linyi, as the most populous medium-sized city in Shandong, is bound to receive more policy and financial support. The national economic layout is favorable, the central government has made a top-level design for the economic development of old regions, and the 14th Five-Year Plan of Shandong Province proposes to promote the development of key regions in the Yimeng Mountains, build a hub for China-European trains in Jinan, Qingdao, and Linyi, and promote the rise of southwest Lu. These external environments and policies provide important impetus for Linyi's economic development. A large amount of capital investment will improve Linyi's environment for air logistics development, attracting air logistics companies to settle in Linyi and promoting air logistics development.

\subsubsection{External Threats}

The development of any industry will lead to competition. The advantages of air logistics in the future economic and social development are becoming more and more obvious and have attracted a large number of entrants. Shandong, Jiangsu, Henan, and other provinces and regions at the prefecture-level, driven by economic development, began to recognize the importance of the development of aviation logistics, increase the construction of aviation logistics, Yantai, Lianyungang, Rizhao, Anyang, and other places are increasing the construction of the airport. In recent years, the construction of high-speed rail has been increasingly accelerated, and the speed of high-speed rail has largely reduced the advantages of air transportation. In addition, the customers of air logistics are becoming more and more changeable, and the requirements for services are getting higher, and the needs are diversified, which brings new challenges to the development of air logistics.

\subsubsection{SWOT matrix analysis}

For the SWOT Matrix Analysis of Linyi aviation logistics development, please refer to Table 2. [3].

Table 2 SWOT Matrix Analysis of Linyi Air Logistics Development

\begin{tabular}{|c|c|c|}
\hline & Strength S & Weakness W \\
\hline $\begin{array}{l}\text { Opportu } \\
\text { nity O }\end{array}$ & $\begin{array}{l}\text { SO Strategic Choice: Strengthen Strengths, } \\
\text { Seize Opportunities } \\
\text { 1. Taking advantage of local logistics } \\
\text { resources to seize the market. } \\
\text { 2. Seizing policy support to accelerate } \\
\text { development. } \\
\text { 3. Strengthen local market development } \\
\text { and increase business space. }\end{array}$ & $\begin{array}{l}\text { WO Strategic Choice: Exploiting } \\
\text { Opportunities, Complementing Disadvantages } \\
\text { 1. Improving the level of information } \\
\text { technology and enhancing management } \\
\text { capabilities. } \\
\text { 2、Steady development of surrounding } \\
\text { markets. } \\
\text { 3、Improve the infrastructure facilities. }\end{array}$ \\
\hline Threat T & $\begin{array}{l}\text { ST Strategic Choice: Leveraging Strengths, } \\
\text { Responding to Threats } \\
\text { 1. Carrying out diversified service } \\
\text { strategies. } \\
\text { 2. Enhance the publicity and expand the } \\
\text { brand effect. }\end{array}$ & $\begin{array}{l}\text { WT strategic choices: responding to } \\
\text { disadvantages and threats, doing something } \\
\text { about it } \\
\text { 1. Strengthen the ability to integrate } \\
\text { resources and establish stable supply } \\
\text { relationships. } \\
\text { 2. Good outreach and cooperation with large } \\
\text { logistics and express enterprises }\end{array}$ \\
\hline
\end{tabular}




\subsection{Strategic choices for the development of aviation logistics in Linyi}

\subsubsection{Strategic goal setting}

Based on the previous analysis, we can find that Linyi's development of air logistics is a combination of opportunities and challenges. To develop, we must strengthen our advantages, make up for our disadvantages and turn threats into opportunities. To this end, the strategic goal of Linyi's air logistics development should be: based on the advantages of local logistics resources, play the support of local economic development, carry out diversified business services, and strive to build into an air logistics hub radiating south of Shandong Province and north of Jiangsu Province. [4]

\subsubsection{VRIO model analysis}

Combining the conclusions of the previous SWOT analysis, the value, scarcity, imitability, and organizational issues of Linyi's internal resources for developing air logistics were analyzed to form the VRIO analysis statement, as shown in Table 3.

Table 3 Analysis of VRIO model for the development of aviation logistics in Linyi

\begin{tabular}{|c|c|c|c|c|}
\hline & Value-based & Scarcity & Inimitable & Organizational \\
\hline $\begin{array}{l}\text { Financial } \\
\text { Capability }\end{array}$ & $\sqrt{ }$ & $\sqrt{ }$ & $x$ & $\sqrt{ }$ \\
\hline $\begin{array}{c}\text { Marketing } \\
\text { capabilities }\end{array}$ & $\sqrt{ }$ & $\sqrt{ }$ & $\sqrt{ }$ & $\sqrt{ }$ \\
\hline $\begin{array}{l}\text { Management and } \\
\text { control capabilities }\end{array}$ & $\sqrt{ }$ & $x$ & $x$ & $\sqrt{ }$ \\
\hline R\&D Capabilities & $\sqrt{ }$ & $\sqrt{ }$ & $\sqrt{ }$ & $x$ \\
\hline $\begin{array}{l}\text { Decision-making } \\
\text { ability }\end{array}$ & $\sqrt{ }$ & $x$ & $x$ & $\sqrt{ }$ \\
\hline $\begin{array}{c}\text { Organizational } \\
\text { and management } \\
\text { skills }\end{array}$ & $\sqrt{ }$ & $x$ & $x$ & $x$ \\
\hline Social Culture & $\sqrt{ }$ & $\sqrt{ }$ & $x$ & $\sqrt{ }$ \\
\hline
\end{tabular}

\subsubsection{Core Competence Positioning}

According to the analysis of the VRIO model for the development of air logistics in Linyi, its core competitiveness is positioned as follows. [5]

(1) Linyi develops air logistics with certain core competencies in finance, marketing, $\mathrm{R} \& \mathrm{D}$, and social culture.

(2) In terms of financial capability, Linyi has a strong economic development capability among the same type of prefecture-level cities.

(3) Linyi's marketing ability to develop air logistics is of most advantageous. It is mainly reflected in the fact that Linyi is an important logistics base in China with a brand effect.

(4) In terms of R\&D, mainly Linyi has an important location advantage and policy support, with sufficient development potential.
(5) In terms of social culture, it is reflected in the fact that Linyi has been developing its logistics economy for many years, and the logistics industry has a strong economic color in the region, forming a certain logistics culture that is easily supported by the community.

\section{LINYI AIR LOGISTICS DEVELOPMENT STEPS AND SUGGESTED MEASURES}

\subsection{Linyi Air Logistics Development Steps}

\subsubsection{Improve the infrastructure}

Infrastructure is the hardware for the development of air logistics. Linyi should increase the construction of the airport, to have parking aprons for any type of aircraft; expand the area of the cargo and mail terminal, improve the cargo warehouse and business premises, to increase the construction of refrigerated warehouses, warehouses for dangerous chemicals, warehouses for valuable items, health, and medical warehouses; to increase freight supporting infrastructure, increase loading and unloading 
transport vehicles, increase security checkers, weighbridges, loading and unloading platforms, Shelves and other infrastructure facilities. In addition, there should be an increase in the construction of customs houses, increased customs, inspection, and quarantine facilities.

\subsubsection{Improve the software infrastructure}

Software is the key to provide good service. Linyi should increase the construction of software in the development of air logistics. We need to increase the construction of aviation logistics information systems to reach an intelligent service platform to realize intelligent information processing and management; to strengthen quality management and build a quality control system matching Linyi's aviation logistics to provide efficient, high-quality, and standardized services to customers; to establish a modern management system, improve the existing organizational structure, clarify the service functions, improve the effectiveness of human resource management and enhance the level of enterprise management.

\subsubsection{Expansion of domestic and international routes}

Routes are the basis of air logistics. In the future development, Linyi Airport must expand the number of domestic and foreign routes and position itself as the hub of air logistics in Southern Jiangsu and Northern Jiangsu. On the one hand, we should increase cooperation with domestic airlines to increase the number of domestic routes and direct airport access; on the other hand, we should actively increase cooperation with foreign airlines and take advantage of the resources of economic and trade exchanges between Shandong and East and Southeast Asia to cooperate with airlines of these countries and regions to build a logistics transit area between inland China and Japan, Korea and Southeast Asian countries.

\subsection{Suggestions for the implementation of competitive strategies for the development of aviation logistics in Linyi}

\subsubsection{Construction of intelligent logistics aviation information platform}

As Linyi is relatively late in the development of air logistics and has a large shortage, it cannot continue the old path of previous air logistics development and should be positioned high in the development and use modern technology and equipment to the maximum extent. Therefore, Linyi in the development of air logistics, first of all, we should make extensive use of information technology to achieve networking, digitalization, and intelligence; secondly, we should build a perfect logistics information system and construct a logistics and freight data warehousing system to collect the information of inbound, outbound, transportation and distribution of goods; finally, we should establish a perfect freight website, which can allow customers to handle all kinds of transportation business online and integrate the customs The relevant processing network interface is integrated together to realize the whole paperless processing of freight logistics.

\subsubsection{Establish a perfect air logistics network}

Linyi airport has fewer routes, which is the shortboard of developing air logistics at present, especially too few international routes, which leads Linyi international logistics to be transferred to Beijing, Shanghai, or Jinan. In future development, Linyi Airport must establish a perfect air logistics network. Firstly, we should improve the cargo source network and establish a perfect logistics network with the regions of Southwest Shandong, North Jiangsu, North Anhui, and East Henan to better undertake cargo transportation in the region; secondly, we should improve the efficient transit network and actively build cooperation with airports in Beijing, Shanghai, Jinan, and other major cities to ensure the timely arrival of transit cargo; finally, we should establish a perfect cargo delivery network and innovate the logistics delivery mode to build a perfectly efficient and fast delivery network. Finally, we should establish a perfect cargo delivery network, innovate logistics delivery mode, build a perfectly efficient and fast delivery network, and realize the one-stop service of "point to point and door to door" logistics delivery.

\subsubsection{Strengthen human resource security}

Human resources are one of the most valuable resources for industrial development. Firstly, Linyi should, on the one hand, increase the training and recruitment mechanism of aviation logistics talents and establish cooperation mechanisms with various universities and colleges for training talents to guarantee the demand of human resources for the strategic development of aviation logistics; secondly, it should establish a perfect incentive mechanism and improve the performance management system to maximize the contribution of employees; finally, it should strengthen the introduction of high-tech talents, especially in the fields of aviation, logistics, management, and information technology Finally, we should strengthen the introduction of high-tech talents, especially in the fields of aviation, logistics, management, and information technology, to enhance the innovation ability of Linyi's aviation logistics enterprises.

\subsubsection{Build stable customer relationships}

Customers are the support of enterprise development. 
Without enough customers, it will not form a sufficient source of development power. Linyi aviation service enterprises should actively build stable customer relationships with customers. Firstly, they should form the consciousness of "customer first," the development goal of the enterprise is to achieve by meeting customer needs; secondly, they should sort out customer needs and design different products according to different customers; finally, they should establish a stable Finally, to establish a stable customer base, timely understanding of customer demand trends, timely participation in the implementation of customer projects.

\subsubsection{Enhancement of industry chain integration capability}

Aviation logistics is a complete industry chain, and Linyi's aviation logistics development is part of the whole aviation logistics industry chain. In order to ensure longterm and stable development, Linyi's aviation logistics enterprises must strengthen their own industry chain integration capabilities. On the one hand, they should establish stable customer relationships with various logistics companies and courier companies to establish subsidiaries or logistics parks in Linyi to ensure stable supply to the upstream industry of aviation logistics; on the other hand, they should develop stable cooperation with major airports and airlines to maximize the number of logistics reachable areas and ensure the radiation of Linyi's aviation logistics industry to the downstream industry.

\subsubsection{Enhancement of brand image}

The brand is the image of an enterprise and the most important intangible resource of an enterprise. Linyi should actively play the brand effect formed in the logistics industry. First of all, we should continue to maintain the quality of air logistics services and establish the external image of "quality first"; secondly, we should obtain the ISO9000 certification system as soon as possible to meet the international requirements; finally, we should strengthen the improvement in infrastructure, services and supporting areas to maximize the quality. Finally, we should strengthen the improvement of infrastructure, services, and supporting areas to maximize the quality.

\subsubsection{Strengthen technological innovation}

In the process of air logistics development, Linyi should increase technological innovation, use new technologies and new ideas to promote air logistics development, and improve the quality of development. Firstly, we should cooperate with transportation logistics universities and research institutes, such as the Linyi Research Institute of Shandong Transportation Institute and other specialized research institutes, to strengthen technological innovation support; secondly, we should strengthen the innovation of technology in freight transportation, loading, and unloading, and distribution to improve service quality; finally, we should invest more in information technology, and use modern information technology to improve the efficiency and accuracy of air logistics, reduce costs and improve profit margins.

\section{CONCLUSION}

The logistics industry is known as the "third source of profit," and all countries and regions around the world are vigorously developing the logistics industry. Linyi, an important logistics base in the north of China, has been developing land logistics for a long time and has a big shortage in air logistics. In the 14th Five-Year Plan, both Shandong Province and Linyi City have positioned Linyi's aviation logistics development as a key development area, which provides an important opportunity for Linyi's aviation logistics development. In view of this, this paper, based on the theories and research methods related to strategic enterprise management and the current research status, analyzes Linyi's external macro environment, internal resources and capabilities, its own strengths and weaknesses, development opportunities and challenges, and positions its core competitiveness, formulates strategies to enhance competitiveness, and proposes corresponding supporting measures. The paper also identifies its core competitiveness, formulates strategies to enhance its competitiveness, and proposes corresponding supporting measures. After the research of this paper, the following conclusions are formed.

First, in terms of the external environment, Linyi has great opportunities in terms of macroeconomic and policy to develop air logistics but also faces the threat of fierce competition in the industry, higher prices from suppliers, strong bargaining power from customers, and entry of substitutes and potential competitors.

Secondly, in terms of internal resources and capabilities, the IFE matrix analysis shows that Linyi's internal resources and capabilities in developing air logistics have more advantages than disadvantages, with an advantage score of $1.76>$ disadvantage score of 1.45 , and its total internal resources and capabilities score is 3.21, which is more than 2.5. This shows that Linyi's internal resources and capabilities in developing air logistics are also at the upper level within the whole industry. This indicates that Linyi's internal resources and capabilities in developing air logistics are at the upper level of the industry, and its internal strengths are higher than the industry average.

Again, in terms of strategic objectives and core competitiveness, after using SWOT analysis and VRIO model, the strategic objectives proposed in this paper for the development of air logistics in Linyi are "to build on 
the advantages of local logistics resources, give full play to the support of local economic development, carry out diversified business services, and strive to build into an air logistics hub that radiates to southern Lu and northern Jiangsu. " It also proposes to enhance the core competitiveness in finance, marketing, $R \& D$, and social culture.

Finally, in terms of development strategies, steps and measures, this paper suggest that Linyi should implement logistics intelligence strategy, management service enhancement strategy, cost leadership strategy, resource integration strategy, and land-air combination strategy to develop air logistics, and implement them in three steps: improving infrastructure, improving software support, expanding domestic and international routes, and putting forward specific measures in terms of information construction, logistics network construction, human resources, customer relations, industrial integration, brand image, and technological innovation. The airport will also need to put forward specific guarantee measures in terms of information construction, logistics network construction, human resources, customer relations, industrial integration, brand image, and technological innovation.

\section{REFERENCES}

[1] Zhang, X. (2015). China's cross-border e-commerce logistics dilemma and suggestions for countermeasures. Contemporary Economic Management, 5, 51-54.

[2] Ma, L. (2008). Research on the development model of the logistics industry cluster.

[3] Mou, S., \& Wang, C. (2008). Acquisition of sustainable competitive advantage in industrial clusters: A perspective based on knowledge absorption capacity. Science and Technology Management Research, 5.

[4] Wei, H. (2008). Industrial Agglomeration and Cluster Strategy in China. Economy \& Management Publishing House.

[5] Ma, L. (2010). Analysis of the formation mechanism of logistics industry cluster based on cluster effect. China Market, 3-4. 